\title{
METAIS PESADOS E QUALIDADE DA AGUA DO RIO SÃO FRANCISCO NO SEGMENTO ENTRE TRÊS MARIAS E PIRAPORA - MG: ÍNDICE DE CONTAMINAÇÃO
}

\author{
Elizêne Veloso Ribeiro ${ }^{1}$; Antônio Pereira Magalhães Junior ${ }^{2}$; Adolf Heinrich Horn ${ }^{3}$; \\ Wallace Magalhães Trindade ${ }^{1}$
}

1 - Programa de Pós-Graduação em Geografia da UFMG, NGQa - CPMTC, Instituto de Geociências, Avenida Presidente Antônio Carlos, 6627, Pampulha. CEP 31270-901. Caixa Postal 719. Belo Horizonte, Minas Gerais, Brasil elizenev@yahoo.com.br; 2 - Departamento de Geografia, Instituto de Geociências, Avenida Presidente Antônio Carlos, 6627, Pampulha. CEP 31270-901. Caixa Postal 719. Belo Horizonte, Minas Gerais, Brasil; 3 DEGEO, NGQa - CPMTC, Instituto de Geociências, Universidade Federal de Minas Gerais- UFMG; Avenida Presidente Antônio Carlos, 6627, Pampulha. CEP 31270-901. Caixa Postal 719. Belo Horizonte, Minas Gerais, Brasil.

Recebido em 17 de abril de 2012; aceito em 16 de maio de 2012

RESUMO: Este trabalho apresenta resultados da avaliação da qualidade da água na secção do Rio São Francisco no segmento entre Três Marias e Pirapora. Foram monitorados parâmetros físico-químicos e os elementos $\mathrm{Zn}, \mathrm{Cd}, \mathrm{Pb}, \mathrm{Cr}, \mathrm{Co}, \mathrm{Cu}, \mathrm{Ba}, \mathrm{Ni}, \mathrm{Al}, \mathrm{Mn}, \mathrm{Ca}, \mathrm{Mg}$ e $\mathrm{Fe}$ durante um ano; as concentrações dos metais foram obtidas por leitura em ICP-OES. Vários elementos apresentaram altos níveis de contaminação nas áreas urbano-industriais de Três Marias e Pirapora. No segmento de influência rural entre os dois centros urbanos e a jusante de Pirapora, foram observadas alterações para os metais pesados ( $\mathrm{Cd}, \mathrm{Cu}, \mathrm{Cr}$, Co e $\mathrm{Ni}$ ), que evidenciam a necessidade de um estudo de contaminação dos solos agrícolas, principalmente irrigados, na região. A variação sazonal marca a diferença da qualidade da água no segmento no que se refere aos metais em suspensão com maiores concentrações na estação chuvosa. O Índice de Contaminação foi definido pela razão entre a concentração encontrada e os limites ambientais da Resolução Conama 357/2005. Os resultados evidenciam a degradação da qualidade da água nos centros urbano-industriais, cujos altos Ic decorrem das elevadas concentrações de Zn, Cd, Cu, Cr e Ni. Chamam atenção principalmente os valores que foram obtidos para os metais dissolvidos devido à maior possibilidade de efeitos tóxicos.. Ressalta-se a necessidade de intervenção nas áreas de maior lc adjacentes aos centros urbano-industriais visando a melhorar a qualidade da água e responder à população local que tem forte relação com o Rio São Francisco.

Palavras-chave: Metais Pesados, Qualidade da Água, Índice de Contaminação, Rio São Francisco e Uso do Solo.

ABSTRACT: HEAVY METALS AND WATER QUALITY OF THE SÃO FRANCISCO RIVER IN SEGMENT BETWEEN TRÊS MARIAS AND PIRAPORA MG: INDEX OF CONTAMINATION. This work presents heavy metal concentration measurements taken across a section of the São Francisco River, between Três Marias and Pirapora, to evaluate water quality. The physicochemical parameters and the elements $\mathrm{Zn}$, $\mathrm{Cd}$, $\mathrm{Pb}$, $\mathrm{Cr}$, Co, $\mathrm{Cu}, \mathrm{Ba}, \mathrm{Ni}, \mathrm{Al}, \mathrm{Mn}, \mathrm{Ca}, \mathrm{Mg}$ and Fe were monitored during a one year period; the concentration levels of metals were determined by ICPOES. High contamination levels were found for many elements in Três Marias and Pirapora urban-industrial areas. The section under rural influence, located between the two urban areas and downstream from Pirapora, presented anomalous heavy metal ( $\mathrm{Cd}, \mathrm{Cu}, \mathrm{Cr}$, $\mathrm{Co}$ and $\mathrm{Ni}$ ) readings. That indicates that soil contamination studies are needed, especially on irrigated soil, in agricultural areas within the region. The index is defined by the ratio between the concentrations found which results from environmental limits established by Resolution CONAMA 357/2005. The results show the degradation of water quality in urban-industrial centers, which high rates of contamination result from high concentrations of $\mathrm{Zn}, \mathrm{Cd}, \mathrm{Cu}, \mathrm{Cr}$ and $\mathrm{Ni}$. The values obtained for dissolved metals are especially worth of attention, due to the greater risk of toxic effects caused by them. We stress the need for intervention in the areas showing the highest contamination index which are located next to urban-industrial centers - to improve water quality and meet the expectations of the locals, whose lives are strongly intertwined with the São Francisco River.

Keywords: Heavy Metals, Water Quality, Contamination Index, São Francisco River and Soil Use

\section{INTRODUÇÃO}

A qualidade da água tem versado como tema fundamental nos estudos acerca dos recursos hídricos continentais, sendo uma variável dependente das características naturais e do uso e ocupação do solo na bacia hidrográfica. A noção de qualidade muitas vezes está relacionada apenas às características organolépticas, como sabor, odor e cor; no entanto, esses fatores estão ligados apenas à sensibilidade humana e não revelam os reais problemas de comprometimento da qualidade das águas.

Alguns parâmetros principais têm sido usados nos estudos da qualidade da água, principalmente aqueles orgânicos, relacionados aos esgotos domésticos e industriais. Os contaminantes inorgânicos têm ganhado uma visibilidade maior com o estudo da contaminação por metais pesados, tendo em vista a toxidade desses elementos. Entretanto, apesar do conhecimento dos problemas associados à presença desses elementos, esses ainda não são integrados aos Índices de Qualidade.

Os metais pesados (Duffos, 2001) referem-se a um grupo de elementos com densidade específica e, principalmente, características de toxidade particulares. Neste trabalho, o conceito de metais pesados será usado considerando sua estreita relação com a toxidade. Esses metais ocorrem naturalmente e podem ter fontes antropogênicas.

A mudança dos padrões dos metais pesados nos corpos hídricos tem impactos significativos na saúde humana e na biota aquática. Os metais pesados incluem alguns elementos que estão presentes nos 
organismos vivos em pequenas quantidades (os denominados micronutrientes essenciais), que se tornam tóxicos com o aumento das concentrações (bioacumulação), enquanto alguns elementos são naturalmente tóxicos.

A análise dos níveis de metais pesados na área de estudo parte da investigação das alterações do uso e ocupação do solo, que vêm se intensificando desde a década de 60, com a expansão das atividades econômicas nos setores industriais e da agropecuária e o consequente crescimento urbano.

Em Três Marias, foram considerados os históricos índices de contaminação por metais, principalmente o zinco (Zn), originados da usina de beneficiamento localizada no município. Durante um longo período, essa usina lançou os efluentes diretamente no Córrego Consciência, afluente direto do Rio São Francisco. Outro ponto de destaque refere-se à entrada do afluente Rio Abaeté, no qual existe intensa atividade de garimpo.

Entre Três Marias e Pirapora, as monoculturas caracterizam um cenário de ampla atividade agropecuária, com grande número de fazendas, a exemplo daquelas que se localizam no alto Chapadão dos Gerais. Destacam-se plantações de pínus, eucalipto, soja, milho, café e recentemente algodão, atividade representativa da sub-bacia do Rio do Formoso, localizada no município de Buritizeiro.

Em Pirapora, destacam-se as atividades industriais e agrícolas. As atividades industriais incluem as metalúrgicas e têxteis, das quais resultam a emissão de particulados atmosféricos e o lançamento de efluentes líquidos. Na agricultura, tem-se a fruticultura, principalmente com a produção de uva e cítricos, além das monoculturas de eucalipto e café.

Este trabalho tem como objetivo principal avaliar a presença e os níveis de concentração de metais pesados na secção do Rio São Francisco a jusante da represa de Três Marias e montante do Rio das Velhas, investigando as possíveis fontes naturais e influências das atividades antropogênicas na qualidade da água e sua identificação no índice de contaminação.

\section{LOCALIZAÇÃO E CARACTERIZAÇÃO DA ÁREA DE ESTUDO}

A área de estudo encontra-se localizada entre as macrorregiões do Noroeste de Minas e Alto São Francisco, englobando na unidade hidrográfica área de 15 municípios. A delimitação da área de trabalho considerou a secção hidrográfica a jusante da represa de Três Marias até a montante da Foz do Rio das Velhas, no município de Pirapora.
Três Marias destaca-se pela presença da usina hidrelétrica da Companhia Hidrelétrica de Minas Gerais (CEMIG), cuja represa define uma nova dinâmica hidrológica ao Rio São Francisco. Outra característica importante é a presença da indústria de beneficiamento de $\mathrm{Zn}$, que tem causado polêmica quanto à contaminação das águas do Rio São Francisco.

O Rio das Velhas é o maior afluente do Rio São Francisco em Minas Gerais. Sua entrada no Rio São Francisco ocasiona mudanças significativas nas características das águas, já que esse rio drena a região metropolitana de Belo Horizonte e as áreas de mineração do quadrilátero ferrífero, apresentando um alto grau de contaminação evidenciado pelas análises do IGAM no projeto Águas de Minas.

A área de estudo (Figura 1) está inserida no Alto/Médio curso do São Francisco, onde a estruturação da drenagem regional e a dinâmica hidrológica estão diretamente relacionadas às litoestruturas que caracterizam a região. As principais áreas de recarga localizam-se nos aquíferos cretáceos do Grupo Areado e das coberturas arenosas do Chapadão dos Gerais; nos sopés das escarpas desenvolveram-se as cabeceiras de drenagem em ambientes de veredas, a partir das quais forma-se uma densa rede de drenagem.

\section{Localização da área de estudo}

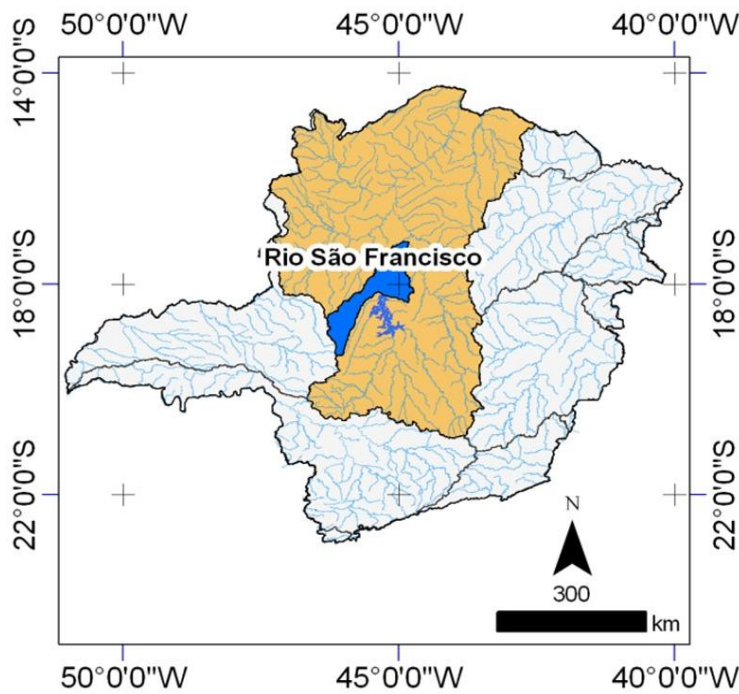

Figura 1 - Mapa de localização da área de estudo no contexto hidrográfico de Minas Gerais e da Bacia do Rio São Francisco.

O Rio São Francisco recebe a contribuição de um grande número de córregos e rios. Dentre os maiores afluentes destacam-se, à margem direita, as sub-bacias do Rio Abaeté e Rio do Formoso, à margem esquerda, o Rio de Janeiro. 


\section{MATERIAL E MÉTODOS}

Os métodos adotados neste trabalho incluíram três fases principais: trabalhos de campo, análises laboratoriais e atividades em gabinete.

Os pontos de coleta das amostras de água totalizaram 60 ao longo do segmento. As coletas de amostras foram realizadas em março, julho e outubro de 2008, sendo a última amostragem realizada em janeiro de 2009. O monitoramento trimestral foi importante devido à intenção de identificar os fatores contaminantes permanentes e sazonais (Figura 2), caracterizados pela significativa diferença climática entre as estações úmida e seca, principalmente pelo carreamento do material superficial e mobilização de materiais presentes nos sedimentos e solos.

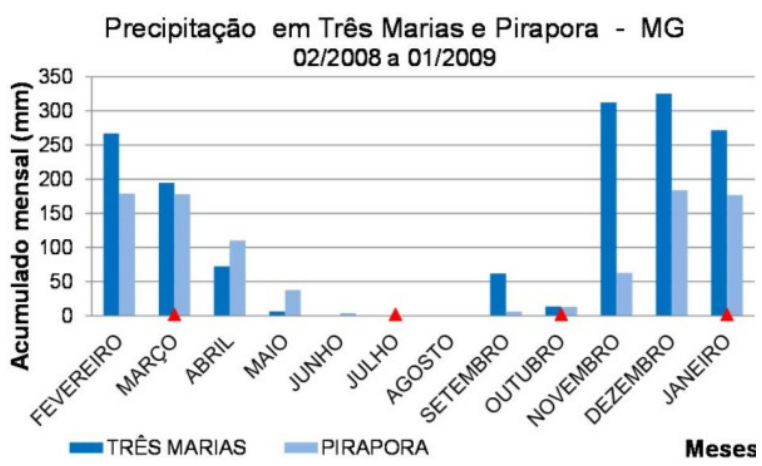

Figura 2 - Precipitação pluvial na área de estudo.

Foram monitorados os parâmetros físicoquímicos Turbidez, STD, Condutividade, Oxigênio Dissolvido, Temperatura e $\mathrm{pH}$, e os elementos $\mathrm{Cd}$, $\mathrm{Pb}, \mathrm{Cr}, \mathrm{Co}, \mathrm{Cu}, \mathrm{Ba}, \mathrm{Ni}, \mathrm{Zn}, \mathrm{Al}, \mathrm{Mn}, \mathrm{Mg}, \mathrm{Ca}$ e $\mathrm{Fe}$ durante um ano. A definição desses elementos considerou a toxidade e o potencial de contaminação das atividades de uso do solo desenvolvidas na região. Os elementos $\mathrm{Al}, \mathrm{Ca}, \mathrm{Mg}$, $\mathrm{Mn}$, Fe destacam-se pela sua influência na disponibilidade dos demais metais.

Para a obtenção dos dados de metais pesados, desenvolveram-se algumas etapas principais, desde a coleta das amostras, filtragem, abertura dos filtros por digestão ácida em microondas e leitura no Espectrômetro de Emissão Atômica (ICP - OES). As leituras resultaram em valores para as concentrações na fração dissolvida, em suspensão e total.

$\mathrm{Na}$ análise estatística foram realizados testes de correlação e médias bem como a Análise de Cluster no programa SPSS e criado um índice de contaminação.

\section{RESULTADOS E DISCUSSÃO}

Os metais analisados comportamento distinto temporalmente e conforme a leitura. Assim, podem ser destacados dois grupos: um primeiro grupo de metais com variação espacial das concentrações relacionadas às fontes difusas e um segundo grupo com relação mais restrita com fontes pontuais de contaminação.

No primeiro grupo, destacam-se o Alumínio, Ferro dissolvido, o $\mathrm{Pb}, \mathrm{Ba}$, Co e $\mathrm{Mn}$ total além do $\mathrm{Mg}$ e Ca. O Al e Fe dissolvido apresentaram maiores concentrações na estação chuvosa com ocorrência de maior contaminação em Pirapora, para o Fe destacam-se também valores elevados em Três Marias. O chumbo, apesar da inadequada metodologia (limite de quantificação do aparelho maior que o limite ambiental), evidencia contaminação na área industrial de Pirapora e no Rio Abaeté, já na fração dissolvida; além disso, vale ressaltar a observação de um aumento considerável dos valores na área agrícola.

Os elementos $\mathrm{Ba}$, Co e $\mathrm{Mn}$ Total apresentaram comportamento semelhante dando destaque às diferentes e elevadas concentrações encontradas no Rio Abaeté e no Córrego Marambaia, em Pirapora. Essas alterações mostram significativa mudança na qualidade da água nesses dois afluentes diretos do Rio São Francisco, ressalta-se no Córrego Marambaia a intensa atividade agrícola.

O cálcio e magnésio, apesar de não serem abordados pela legislação, mostraram-se muito eficientes na associação à poluição urbana e industrial, já que apresentaram valores diferenciados em Três Marias. As altas concentrações na fração dissolvida, encontradas próximo à área urbana/industrial em Três Marias, foram posteriormente confirmadas pelos demais metais pesados.

Os valores dos metais $\mathrm{Cu}, \mathrm{Cd}, \mathrm{Cr}, \mathrm{Ni}$ e $\mathrm{Zn}$ destacaram-se pelas concentrações embasarem a identificação de elevados índices de contaminação associados a fontes pontuais. Além da toxidade desses elementos e a representatividade das concentrações na degradação da qualidade da água.

\subsection{Cobre $(\mathrm{Cu})$}

A maior porcentagem das leituras para $\mathrm{Cu}$ foram menores que o limite de detecção (LD). Em março, julho e outubro, foram quantificados teores de $\mathrm{Cu}$ dissolvido (Figura 3).

$\mathrm{Na}$ amostragem de março, valores maiores que o LD foram observados entre os pontos $\mathrm{P} 40(0,001 \mathrm{ppm})$ e $\mathrm{P} 47(0,002 \mathrm{ppm})$; nessa mesma área, em julho ocorreu uma detecção no $\mathrm{P} 44(0,002 \mathrm{ppm})$. Esses valores obtidos nesses pontos estão entre o LD e o limite de quantificação (LQ), mas os mesmos são mencionados tendo em vista 
serem os únicos acima do LD ao longo do Rio. Condições semelhantes também foram observadas entre os pontos P34 e P39, em outubro, comportamento semelhante observado para outros metais nessa área.

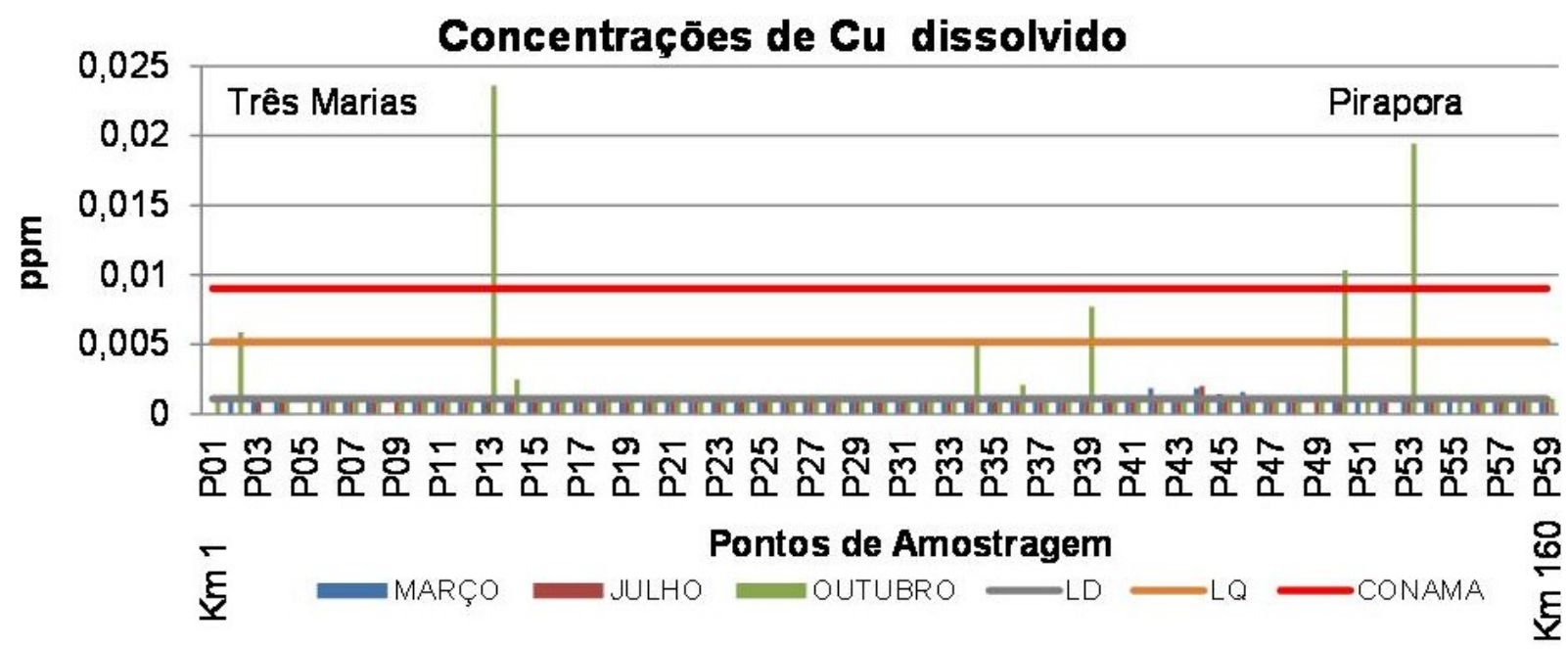

Figura 3 Cobre dissolvido

Em outubro, em nove pontos, foram obtidos valores acima do LD, dentre esses, três pontos apresentaram níveis de contaminação. A contaminação ocorreu a montante do Córrego São José (P13 - 0,023ppm), Córrego das Pedras (P50 $0,01 p p m)$ e próximo às indústrias (P53 - 0,019).

O primeiro ponto (P13) localiza-se no Rio São Francisco a $10 \mathrm{~km}$ de Três Marias, onde permanece a influência turística do lago pela intensa ocupação por sitiantes. O P50 (Córrego das Pedras) localiza-se na área do centro urbano de Buritizeiro, sendo um afluente da margem esquerda do Rio São Francisco. Sua bacia de drenagem caracteriza-se por um ambiente bastante antropizado pelo espaço urbano e atividades de suinocultura, além da influência de atividades industriais que levam à deposição de materiais particulados no solo, plantas e lâmina d'água.

No material particulado em suspensão (MPS) as concentrações de $\mathrm{Cu}$ ficaram entre o mínimo 0,04ppm em outubro e o máximo 0,8 ppm em março de 2008. Não foram observadas diferenças tão significativas entre o período seco e úmido, e as médias foram bastante semelhantes em julho, outubro e janeiro. Maiores concentrações de $\mathrm{Cu}$ em suspensão foram observadas em março.

A semelhança dos resultados nas diferentes estações pode ser relacionada à maior solubilidade desse elemento, permitindo uma maior movimentação na interface água-sedimento, mesmo durante o período de menor quantidade de MPS na água.

Quanto à distribuição espacial, os maiores valores estão nos primeiros $50 \mathrm{~km}$ do Rio São Francisco, a montante do Rio de Janeiro, em todas as amostragens. Valores altos foram observados no Córrego Consciência (P4) - 0,7ppm) e no Rio Abaeté (P16) em março. Em julho, o maior valor ocorreu na área dos sitiantes, corroborando o alto valor de $\mathrm{Cu}$ dissolvido encontrado nesse ponto em outubro; destaca-se ainda nessa amostragem a concentração observada a jusante do efluente industrial (P55).

\subsection{Cádmio (Cd)}

As concentrações de $\mathrm{Cd}$ dissolvido foram menores que as de LD na maioria das amostras. $O$ Córrego Consciência (P4) apresentou altos teores em março $(0,122 \mathrm{ppm})$ e janeiro $(0,027 \mathrm{ppm})$; em outubro, valores altos de $\mathrm{Cd}$ foram obtidos no Córrego das Pedras (P50 - 0,024ppm) e próximo às indústrias (P53-0,039ppm).

Valores entre o LD e o LQ foram encontrados entre os pontos 40 e 47 em março. Em julho, foram quantificados os pontos 43, 49, 53, 54 e 56. Em outubro, uma quantidade maior de leituras foi obtida sendo no Córrego Barreiro Grande (P2), Córrego Aldedo Dourado (P6), jusante do Córrego Lucinda (P9), P12 e a jusante do ponto 27. Em janeiro, esses valores foram obtidos entre os pontos 2 e 43.

No MPS, as concentrações de $\mathrm{Cd}$ em suspensão foram obtidas somente nos meses de março e janeiro no Córrego Barreiro Grande (P2 - 0,01ppm), Consciência (P4 - 0,05ppm) e no Rio Abaeté (P16 $0,007 \mathrm{ppm})$. Em janeiro, além dos afluentes citados, foram quantificados os pontos 21, 23 e entre 27 e 47 , cujas leituras ficaram entre o LD e o LQ.

As concentrações totais de $\mathrm{Cd}$ acima do permitido pelas normas legais ocorreram no Córrego Consciência (P4) e Rio Abaeté (P16), em março e janeiro (Figura 4). Em janeiro, inclui-se ainda o 
Córrego Barreiro Grande (P2). No córrego Consciência, as concentrações de $\mathrm{Cd}$ estavam acima do limite máximo já na fração dissolvida, enquanto no Córrego Barreiro Grande e no Rio Abaeté os maiores teores estão associados ao MPS.

Níveis de contaminação ocorreram também no Córrego das Pedras (P50) e próximo às indústrias (P53); os altos valores de Cd encontrados nesses pontos foram obtidos na amostragem de outubro na fração dissolvida.

Os valores de Cd observados ao longo do Rio São Francisco e afluentes confirmam os níveis de contaminação próximos a Três Marias e Pirapora. Os teores entre o LD e o LQ, obtidos nas duas frações, chamam a atenção para a correlação de concentrações encontradas no MPS em janeiro e na fração dissolvida nas quatro amostragens. É importante salientar que nessa área as alterações encontradas para $\mathrm{Cd}$ também ocorreram para o $\mathrm{Cu}$ na fração dissolvida em março e outubro, como descrito no tópico anterior.

\subsection{Cromo $(\mathrm{Cr})$}

$\mathrm{Na}$ fração dissolvida, as maiores concentrações de $\mathrm{Cr}$ foram obtidas na estação seca. Em julho de 2008, as medições ocorreram nos primeiros $70 \mathrm{~km}$ do Rio, do P03 ao P11 e entre o P24 e P27. No segmento a jusante, somente na área do efluente industrial (P54) foi quantificado $\mathrm{Cr}$ dissolvido. Nessa mesma área do distrito industrial, verificou-se a única quantificação em outubro no P53. Na estação chuvosa, não houve concentrações acima do LQ para $\mathrm{Cr}$ dissolvido; no entanto, em março, no P54 (supracitado) e no P57 (fruticultura), foram obtidas concentrações entre o LD e o LQ.

As concentrações de $\mathrm{Cr}$ em suspensão foram maiores na estação chuvosa. Entre o Rio Abaeté (P16) e a montante da cidade de Pirapora (P49), todos os pontos apresentam altas concentrações de $\mathrm{Cr}$ em suspensão com valores acima do permitido pela legislação, situação característica da amostragem de março e janeiro. Em março, também foram encontradas altas concentrações de $\mathrm{Cr}$ em suspensão nos afluentes Córrego Barreiro Grande (P2 - 0,09ppm) e Consciência (P4 - 3,81ppm), a jusante do Córrego Aldedo Dourando (P6 - 0,21ppm) e no Rio Espírito Santo (P11 - 0,07ppm), bem como nos pontos do segmento a jusante da cidade de Pirapora.

Na estação seca, valores acima do permitido pela legislação ocorreram apenas no Rio Abaeté (P16), no Rio de Janeiro (P23), a jusante do Córrego
Marambaia (P47), em julho, e na área do efluente industrial (P54) em julho e outubro (Figura 5).

Considerando o limite máximo de 0,05ppm, chama a atenção os níveis de contaminação para o $\mathrm{Cr}$ em suspensão que ocorreram na estação chuvosa, principalmente nos afluentes próximos a Três Marias (P2, P4, P7, P11), e a jusante do Abaeté. $\mathrm{Na}$ estação seca, destacam-se contaminações nos afluentes (Rio Abaeté e Rio de Janeiro) e no distrito industrial de Pirapora.

\subsection{Níquel (Ni)}

As detecções de $\mathrm{Ni}$ dissolvido restringiram-se ao Ribeirão do Atoleiro (P32 - 0,012ppm) e ao Córrego Cedro (P36) em março. Em outubro, os maiores teores ocorreram no Córrego das Pedras (P50 $0,12 \mathrm{ppm}$ ) e na área das indústrias em Pirapora (P51 e P53). Menores concentrações foram obtidas entre o P32 e P49. Dentre essas leituras, destacam-se o $\mathrm{P} 51(0,016 \mathrm{ppm})$ e $\mathrm{P} 53(0,32 \mathrm{ppm})$, bem mais elevados que o LQ.

No MPS, maiores concentrações de Ni ocorreram na estação chuvosa. Em março, no Córrego Consciência (P4) e a jusante do Aldedo Dourado (P7), foram encontrados os maiores valores de $\mathrm{Ni}$ em suspensão. A jusante do Rio Abaeté (P16), a maioria dos pontos foi quantificada com concentrações entre 0,02 e 1,5 ppm. Em julho, foi registrado apenas um valor entre o $L D$ e $L Q$ na área do efluente industrial (P54); em outubro, a situação é semelhante, com quantificações no Rio Abaeté (P16) e a jusante do Formoso (P46).

A maioria dos pontos nos quais houve a detecção do Ni em suspensão em março apresenta-se acima do limite permitido. Níveis de contaminação por $\mathrm{Ni}$ também foram encontrados nos dois pontos, com quantificação na amostragem de janeiro: no Rio Abaeté (P16) e a jusante do Rio do Formoso (P46). Nos pontos 34, 39 e 40, também foram encontradas concentrações de $\mathrm{Ni}$ acima do limite permitido na fração dissolvida em outubro. Nessa amostragem, destacam-se concentrações 5 e 13 vezes maiores que o máximo permitido no Córrego das Pedras (P50) e na área industrial (P53).

Os níveis de contaminação (Figura 6) para $\mathrm{Ni}$ estão associados ao MPS em março e à fração dissolvida em outubro. As altas concentrações verificadas em outubro são mais preocupantes uma vez que foram encontradas na fração dissolvida, com maior possibilidade de entrada na cadeia alimentar e possível efeito tóxico na biota. 


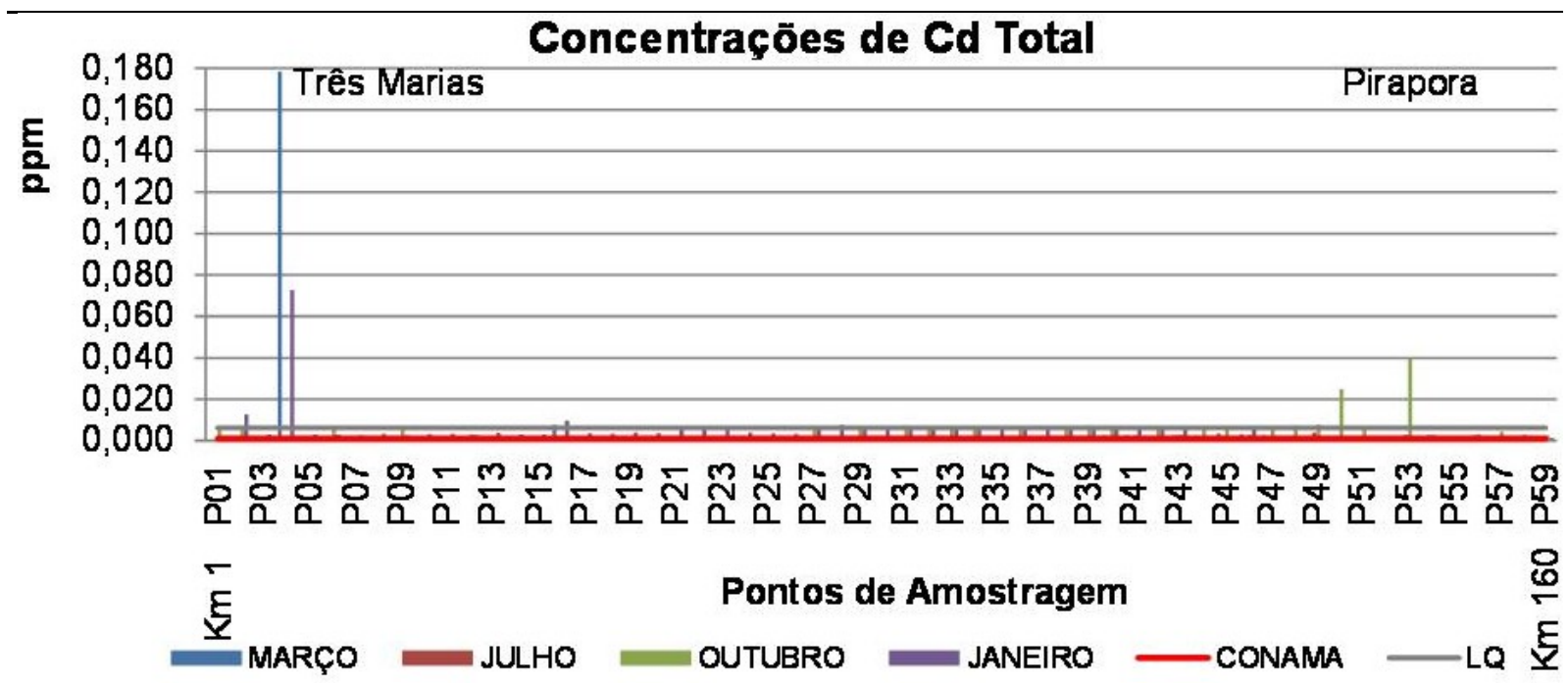

Figura 4 - Cádmio Total

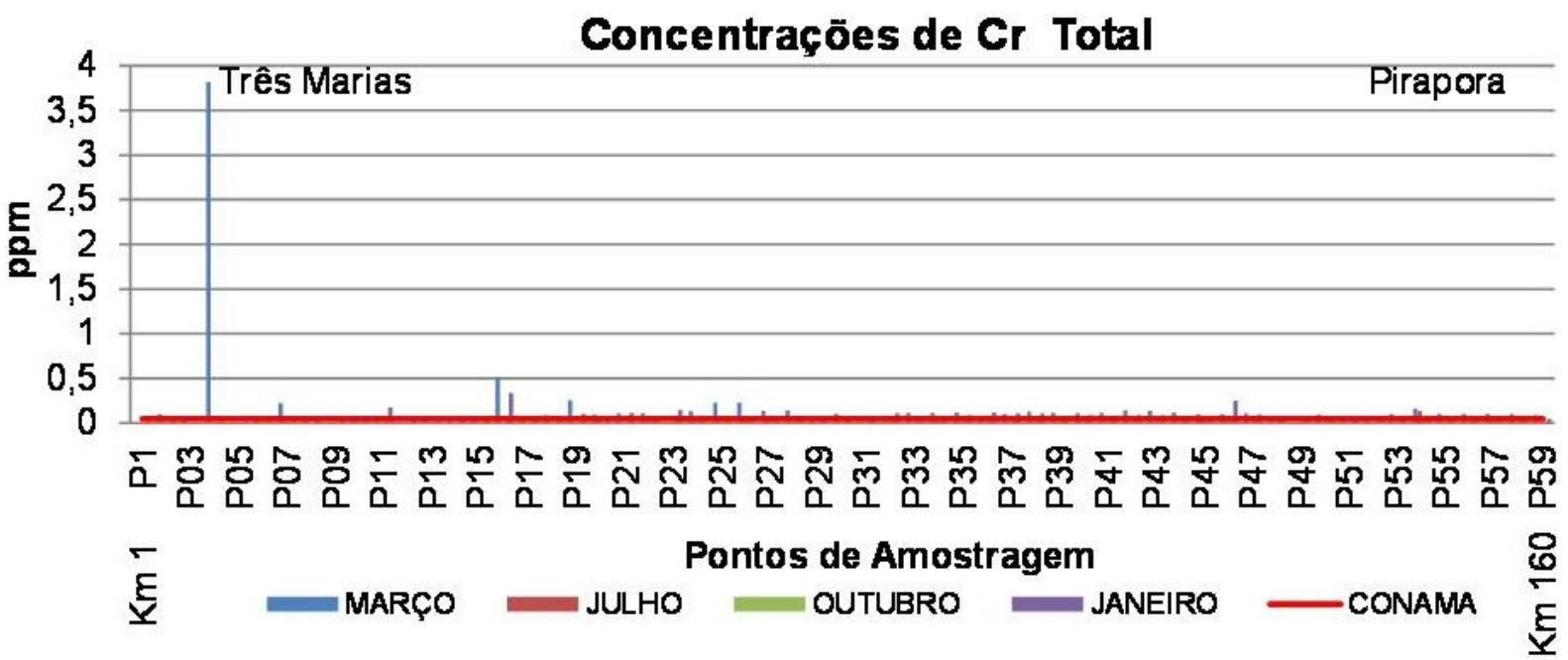

Figura 5 - Cromo Total

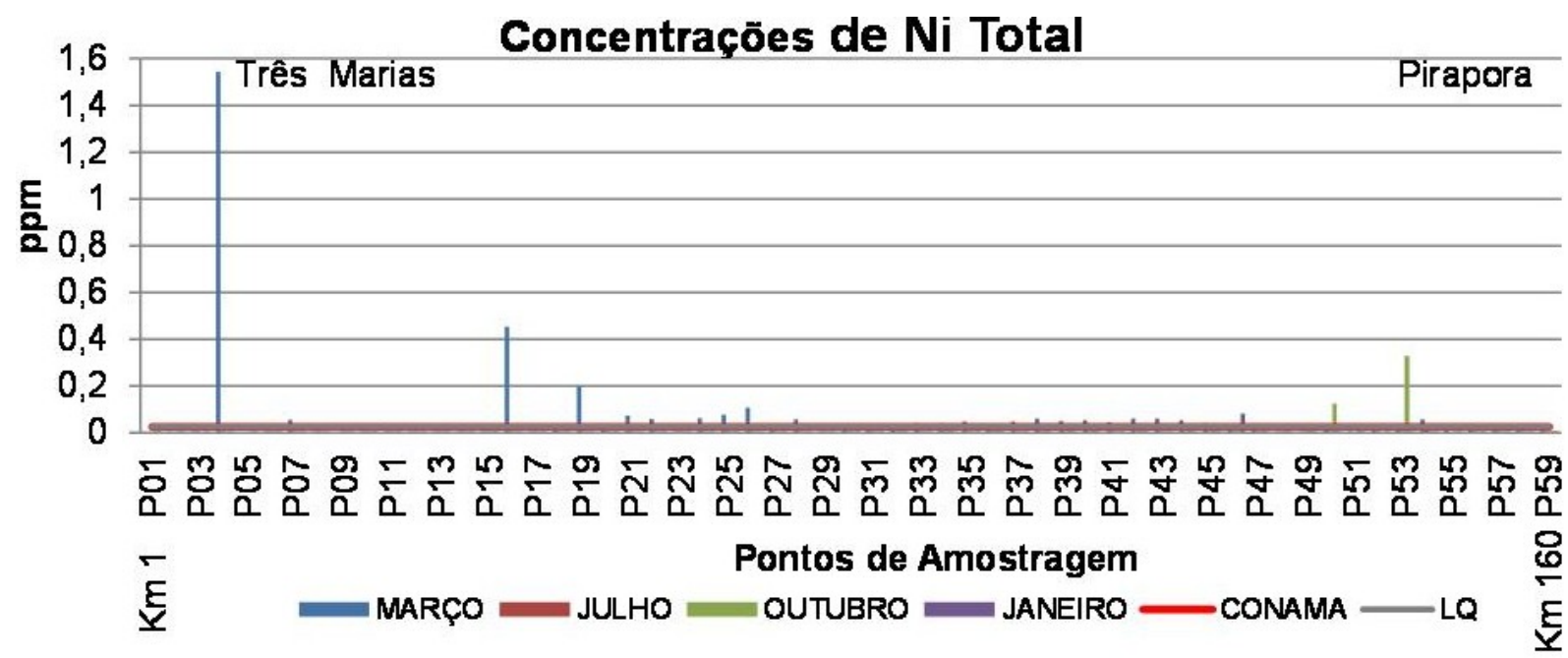

Figura 6 - Níquel total 


\subsection{Zinco (Zn)}

A estação chuvosa apresentou os maiores valores de $\mathrm{Zn}$ dissolvido, e, em outubro, algumas concentrações foram menores que o LD. As maiores concentrações localizam-se próximo a Três Marias, entre os pontos 2 e 5 . Os valores mais altos estão no Córrego Consciência (P4 - 29,1ppm), nos pontos a montante (P3 - 0,31ppm e P2 - 0,19ppm) e a jusante (P5 - 0,14ppm).

No MPS, as concentrações foram semelhantes nas estações seca e chuvosa, principalmente no segmento próximo a Três Marias. Entre os pontos P2 e P5, foram encontrados altos valores, que são similares às concentrações encontradas na fração dissolvida.

Em relação ao limite máximo permitido pela legislação, na estação chuvosa, a maioria dos pontos apresenta Zn acima do limite permitido (Figura 7). Essa contaminação está associada ao metal em suspensão. No Córrego Consciência (P4), os valores estavam acima do permitido em todas as amostragens já na fração dissolvida, comportamento observado também a montante do Córrego Barreiro Grande (P3) em março, e no Barreiro Grande (P2), em janeiro.

Na área próxima a três Marias, as concentrações estão entre 1,6 e 180 vezes o máximo permitido, revelando a forte influência dos efluentes industriais enriquecidos em $\mathrm{Zn}$ nessa área. Os pontos localizados na área de influência das indústrias em Três Marias e Pirapora apresentaram níveis de contaminação em todas as amostragens.

$\mathrm{Na}$ estação chuvosa, foram verificados valores acima do permitido na maioria dos pontos a jusante da área de influência da indústria. No entanto, os níveis de contaminação foram menores, ultrapassando, no máximo, 4 vezes o limite permitido. Essas maiores concentrações, associadas ao MPS ao longo do segmento, podem refletir a quantidade desse metal que pode estar presente nos sedimentos de leito. Os valores encontrados ao longo do segmento no Rio São Francisco não estão relacionados unicamente à indústria, uma vez que foram encontrados valores elevados, com picos no P40 e P47, onde existe uma influência maior da agricultura e da pecuária.

\subsection{Distribuição Espacial das Concentrações dos Metais em Relação ao Uso do Solo}

A relação da contaminação por metais com o uso e ocupação do solo pode ser apresentada em três áreas principais descritas abaixo.

4.6.1. Três Marias: Área de Influência da Indústria de $\mathrm{Zn}$ e do Centro Urbano

As altas concentrações de metais pesados encontradas próximo à cidade de Três Marias em estudos realizados pelo Cetec (1980), Lundhamer (1991), Mozeto (2001) e Oliveira (2007). Estas pesquisas objetivaram conhecer as concentrações de metais na água ou sedimentos na área de influência da indústria de beneficiamento de zinco.

Oliveira (2007) aponta que as concentrações de metais pesados diminuíram entre 1980 e 2006 provavelmente por haver um maior controle de efluentes, a exemplo do observado na indústria de Zn. Nas análises de água realizadas por essa autora, entre 2004 e 2006, foram encontradas altas concentrações de Zn total nos córregos Barreiro Grande e Consciência nas amostragens de outubro/2005 e março/2006. Alterações de Cu no Córrego Consciência e $\mathrm{Cr}$ na margem esquerda e direita também foram observadas nessa área.

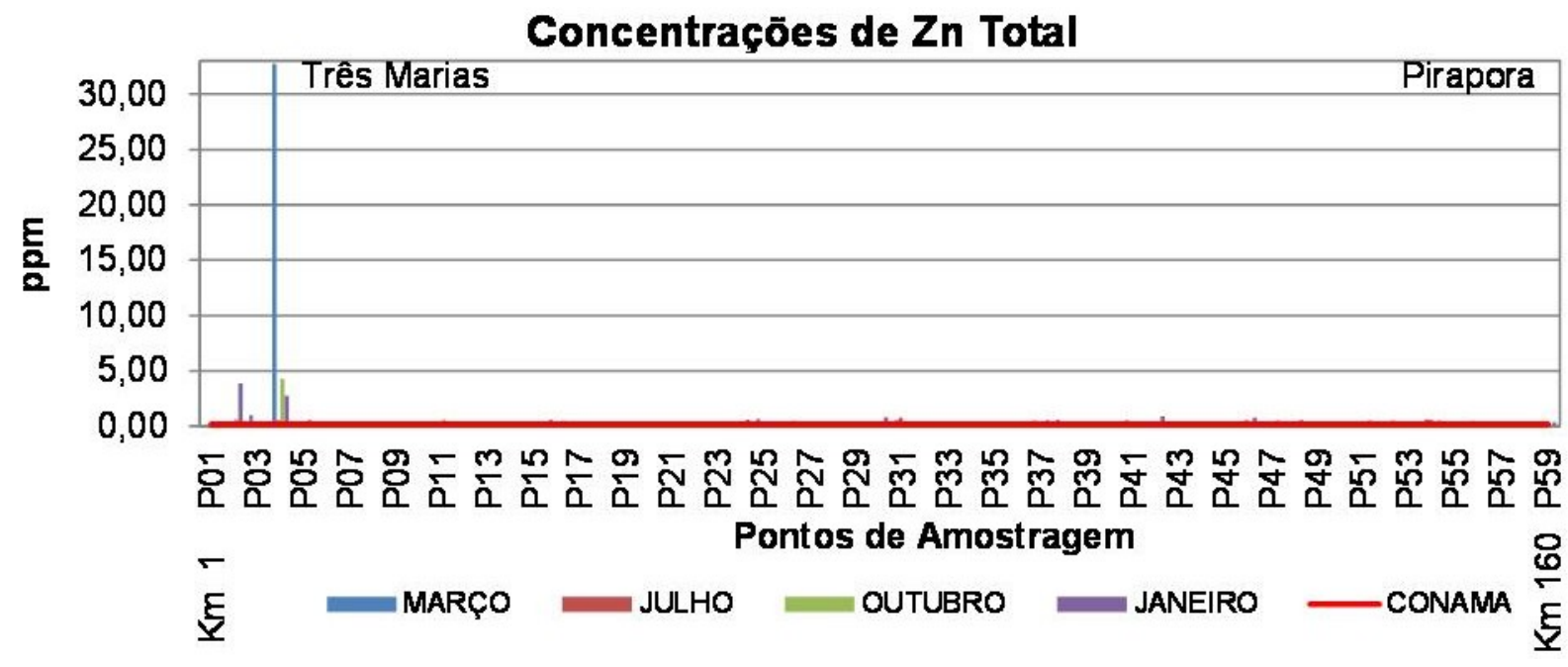

Figura 7- Zinco total 
Neste trabalho, foram encontradas altas concentrações de $\mathrm{Zn}$ dissolvido e em suspensão no Córrego Barreiro Grande e Consciência e entre esses dois córregos na margem direita do Rio São Francisco.

No Córrego Barreiro Grande, também foram verificados valores altos de $\mathrm{Cd}$ dissolvido e em suspensão e de $\mathrm{Cr}$ em suspensão; nesse ponto, apesar da diminuição da influência da indústria de Zn nos últimos anos, tem aumentado a influência dos efluentes doméstico/urbano com o crescimento da população urbana.

O Córrego Consciência, além dos maiores níveis de Zn dissolvido e em suspensão, apresentou também maiores concentrações de $\mathrm{Cd}$ dissolvido e em suspensão, de $\mathrm{Co}, \mathrm{Cr}$, Cu e Ni em suspensão e de $\mathrm{Pb}$ dissolvido. As altas concentrações desses elementos ocorreram na estação chuvosa e estão relacionados à movimentação e à solubilização dos metais ainda presentes nos sedimentos de fundo e da própria barragem de rejeito localizada na área.

Nessa área próxima a Três Marias, foram observados menores valores de $\mathrm{pH}$ e OD e maiores valores de Condutividade associados aos dois pontos de contaminação descritos acima. Foram verificadas, ainda, maiores concentrações de $\mathrm{Mg}, \mathrm{Mn}$ e $\mathrm{Ca}$ dissolvido; a maior quantidade desses elementos na fração dissolvida é viabilizada pelo maior acidez da água na área.

A amplitude da influência dessas contaminações pode ser observada em maiores valores no Rio São Francisco até $3 \mathrm{~km}$ a jusante da foz do Córrego Consciência. Fica evidente que a diluição das concentrações ocorre em função do próprio volume de água do Rio São Francisco.

\subsubsection{Centros Urbanos de Pirapora e Buritizeiro:} Distrito Industrial

Na área de Pirapora, está clara a influência dos efluentes particulados e líquidos do distrito industrial. Altas concentrações de metais foram encontradas numa trecho de $5 \mathrm{~km}$ do Rio São Francisco a montante do distrito Industrial.

Os metais $\mathrm{Co}, \mathrm{Cd}, \mathrm{Cu}$ e $\mathrm{Ni}$ dissolvidos apresentaram comportamento semelhante no Córrego das Pedras (P50) e no (P53) na área em frente às indústrias. Altas concentrações de $\mathrm{Pb}$ e $\mathrm{Cr}$ foram observadas no (P53) e na área do efluente liquido do distrito industrial (P54). Nesse último, foram obtidos menores valores de $\mathrm{pH}$ e $\mathrm{OD}$ e altos valores de Condutividade.

Variações nas concentrações de $\mathrm{Mg}, \mathrm{Mn}$ e $\mathrm{Ba}$ também foram verificadas neste segmento do Rio São Francisco, mostrando a interferência das atividades antrópicas nos teores de metais e qualidade da água.

\subsubsection{Influência da Agropecuária}

Considerando, principalmente, os resultados para a fração dissolvida dos metais, foram identificados os seguintes conjuntos de variação espacial nas concentrações de alguns elementos: no segmento a jusante do Rio de Janeiro (P23), a montante da cidade de Pirapora (P48) e na área do Projeto de Fruticultura (P56-P58), a jusante da cidade de Pirapora.

No segmento a montante de Pirapora, concentrações de $\mathrm{Cu}, \mathrm{Cr}, \mathrm{Mn}, \mathrm{Co}, \mathrm{Ba}$ e $\mathrm{Pb}$ dissolvido tiveram considerável aumento e a deteç̧ão foi restrita a esse segmento. Para o $\mathrm{Cd}$ e o $\mathrm{Ni}$, esse comportamento ocorreu para a fração dissolvida e em suspensão.

$\mathrm{Na}$ área do Projeto de Fruticultura, o ponto com maiores concentrações refere-se àqueles mais próximos da área de plantio, local, inclusive, onde está instalada a estação de captação de água da CODEVASF (P57). Nessa área, chama a atenção a presença de $\mathrm{Cd}, \mathrm{Cr}$, Co, Ba e $\mathrm{Mn}$, que podem estar relacionados aos agroquímicos utilizados no manejo das culturas.

Esses resultados fornecem embasamento para o desenvolvimento de estudos mais específicos para se avaliar a influência das atividades agropecuárias na qualidade da água do Rio São Francisco.

\section{7. Índice de Contaminação por Metais} Pesados

A análise conjunta de todos os metais foi realizada com a criação de um Índice de Contaminação. Esse índice foi calculado tendo como referência os Limites da Resolução CONAMA/357. O peso de cada elemento foi considerado em função da própria variação dos limites definidos pela legislação, uma vez que valores máximos menores estão associados a elementos com toxidade mais elevada, e valores máximos maiores são definidos para elementos menos tóxicos, o que caracteriza um peso diferente para cada um desses elementos no que se refere à qualidade ambiental.

Para calcular o índice, primeiramente foi calculado o Fator de Contaminação (Fc) para cada um dos elementos. Laybauer (1995), Eleutério (1997) e Oliveira et al (2005) adotaram o cálculo do Fc na quantificação da contaminação. Para calcular o Fc, esses autores utilizaram um ponto de controle representativo do background da área estudada.

Segundo Oliveira et al. (2005), na proposta de Tomlison et al. (1980) o Fc é definido como a razão entre a concentração no ponto amostrado e o background, Rodrigues \& Nalini Jr (2009), da região, 
ou seja, quantas vezes o metal analisado ultrapassa o nível de base proposto para a região. Para este trabalho, foram utilizados como background os Limites Máximos estabelecidos pela resolução CONAMA 357 de 2005. Assim, o Fc mostra quantas vezes a concentração está acima do permitido pela legislação ambiental.

O Índice de Contaminação (Ic) foi calculado a partir da soma dos Fc para cada ponto, utilizando os parâmetros físico-químicos e os metais pesados. Essa soma mostra a diferenciação dos níveis (acumulado) de contaminação nos pontos.

O mapeamento da qualidade da água foi realizado por meio do Índice de Contaminação (Ic) em cada ponto monitorado. No Ic foram utilizados os metais $\mathrm{Al}, \mathrm{Cr}$, Fe, Co, Cu, Cd, Mn, Ni, Zn e Ba.

Dentre os metais que possuem limites estabelecidos pela legislação, somente o $\mathrm{Pb}$ não foi utilizado devido ao limite de detecção do aparelho, que já é acima do permitido, não viabilizando a interpretação da contaminação pontual e sim somente a variação ao longo do perfil, como foi descrito no tópico sobre o referido metal.

O Ic por metais dissolvidos em março variou entre 1 e 310. Essa diferença reflete a variação da quantidade dos metais que determinaram a contaminação bem como a proporção em relação ao limite ambiental. Dentre todos os pontos contaminados por metais dissolvidos em março, destaca-se o Córrego Consciência (P4), no qual essa contaminação tem peso especifico dos metais $\mathrm{Cd}$, $\mathrm{Mn}$ e Zn. No Córrego Barreiro Grande (P3), a contaminação é determinada exclusivamente pelo Zn, que se encontra em concentração acima do permitido.

Nos demais pontos, o Ic por metais dissolvidos é determinado pela variação das concentrações de Al e Fe, respectivamente. Esses elementos, apesar de também condicionarem alterações na qualidade da água, são menos tóxicos, não representando a maior preocupação em relação à toxidade, mas revelando condições locais que definem uma qualidade diferenciada para essas águas superficiais.

Para as concentrações totais dos metais em março de 2008, o Ic apresenta uma maior variação, tendo em vista a presença dos metais associados ao MPS. Essas variações foram observadas para o $\mathrm{Cd}$ no Córrego Consciência (P4) e no Rio Abaeté (P16). Concentrações altas de $\mathrm{Ni}$ também foram observadas no Córrego Consciência (P4), entre os córregos Aldedo Dourado e Lucinda (P7), e no Rio Abaeté ( $P 16)$, bem como entre os pontos 18 e 45 e a jusante no distrito industrial de Pirapora (P54).

O Bário também se destaca no Ic no Rio Abaeté (P16) e a jusante do (P19). Comportamento semelhante pode ser observado para o Co no Córrego Consciência (P4), Córrego Espírito Santo (P11) e Rio Abaeté (P16). Além desses afluentes, foram verificadas influências do Co entre o (P19) e (P47), na área do distrito industrial de Pirapora (P53 e 54) e a jusante da Fruticultura (P58). Os valores de $\mathrm{Cr}, \mathrm{Mn}$ e $\mathrm{Zn}$ foram altos em todo o perfil, variando entre 2 e 5 vezes o limite permitido; no entanto, destacam-se os altos valores nos Córregos Consciência (P4), Rio Abaeté (P16) e na área do efluente Industrial em Pirapora, com valores entre 7 e 200 vezes o limite ambiental.

O Ic para os metais dissolvidos em julho de 2008 restringiu-se ao Córrego Consciência (P4) determinado pelo $\mathrm{Zn}$ em concentrações de 2,1 vezes acima dos valores permitidos $(110 \%$ de inconformidade legal).

Considerando os metais em suspensão, destacase a contaminação por $\mathrm{Cr}$, Ni e Co no distrito industrial de Pirapora (P54). Nos demais pontos, as alterações estão relacionadas à presença do $\mathrm{Mn}$ e $\mathrm{Zn}$ associados ao MPS. Para esses metais, a contaminação ocorre ao longo do perfil, mas o Ic é significativamente mais baixo.

Ainda em outubro de 2008, quando a fração em suspensão é associada às concentrações dos metais, mudanças no lc podem ser observadas no distrito industrial de Pirapora (P54), com o Cr, Zn e Mn, e no Rio Abaeté (P16), Rio de Janeiro (P23), Ribeirão do Atoleiro (P32) e a jusante do Córrego Marambaia (P47 - início da área das lagoas marginais), com o Cr, resultando no aumento do Ic nesses pontos. Nos demais, destaca-se o Mn suspenso.

O Ic em janeiro de 2009 não apresentou valores elevados, obtendo o maior índice no Córrego Consciência (P4) pelas concentrações de $\mathrm{Zn}$ e $\mathrm{Cd}$, e no Córrego Barreiro Grande (P2) com o Zn. Os demais valores foram determinados pelas concentrações de Al, Fe e Mn. Para esse último, destaca-se sua presença apenas na área do Projeto de Fruticultura (P58).

O Ic para os metais totais em janeiro apresentase bastante elevado no Córrego Barreiro Grande (P2), no Consciência e nos Rios Espírito Santo, Abaeté e Rio de Janeiro. Esses altos lc estão associados, especificamente, à presença dos metais $\mathrm{Co}, \mathrm{Cr}, \mathrm{Cd}, \mathrm{Ni}$ e $\mathrm{Ba}$, tendo em comum altas concentrações de $\mathrm{Mn}$ e Zn. Ainda pode-se destacar o Ic a jusante do córrego Marambaia (P46), associado à presença de $\mathrm{Co}, \mathrm{Cr}$, Ni e $\mathrm{Ba}$. $\mathrm{O} \mathrm{Cr}$ influencia também os Ic entre o (P25 e P49). Zn e Mn apresentam níveis de contaminação ao longo de todo o perfil, sendo o fator de contaminação do $\mathrm{Mn}$ significativamente maior. 
Tabela 1 - Valores mínimo e máximo do Índice de Contaminação por metais.

\begin{tabular}{|c|c|c|c|c|c|}
\hline \multicolumn{6}{|c|}{ Variação do Índice de Contaminação } \\
\hline \multicolumn{2}{|c|}{ Amostragem e Metais } & \multirow{2}{*}{$\begin{array}{c}\text { Ic Mínimo } \\
1\end{array}$} & \multirow{2}{*}{\begin{tabular}{|c|} 
Ic Máximo \\
310 \\
\end{tabular}} & \multirow{2}{*}{$\begin{array}{c}\text { № de Pontos } \\
\text { Contaminados }\end{array}$} & \multirow{2}{*}{$\begin{array}{l}\text { Metais Principais } \\
\mathrm{Cd}, \mathrm{Mn} \text { e } \mathrm{Zn}\end{array}$} \\
\hline Março & Dissolvidos & & & & \\
\hline & Dissolvidos e Totais & 4 & 693 & 55 & $\mathrm{Cd}, \mathrm{Co}$ e $\mathrm{Ni}$ \\
\hline \multirow[t]{2}{*}{ Julho } & Dissolvidos & 0 & 2 & 1 & Zn \\
\hline & Dissolvidos e Totais & 1 & 22 & 51 & $\mathrm{Cr}$, Ni e Co \\
\hline \multirow[t]{2}{*}{ Outubro } & Dissolvidos & 2 & 60 & 26 & $\mathrm{Zn}, \mathrm{Cu}, \mathrm{Cd}, \mathrm{Ni}$ e $\mathrm{Co}$ \\
\hline & Dissolvidos e Totais & 1 & 64 & 48 & $\mathrm{Cr}, \mathrm{Zn}$ e $\mathrm{Mn}$ \\
\hline \multirow[t]{2}{*}{ Janeiro } & Dissolvidos & 1 & 35 & 9 & $\mathrm{Zn}, \mathrm{Cd}$ \\
\hline & Dissolvidos e Totais & 1 & 116 & 59 & $\mathrm{Co}, \mathrm{Cr}$, Ni e Ba \\
\hline
\end{tabular}

O Ic reflete bem a qualidade da água no Rio São Francisco. Analisando o Ic com a fração dissolvida, percebe-se que os problemas de contaminação estão em pontos específicos nos centros urbanoindustriais, o que facilita processos de gestão e intervenção para melhorar a qualidade da água do Rio São Francisco.

Considerando os metais em suspensão, os problemas de contaminação se ampliam. No entanto o Ic em geral está relacionado principalmente ao $\mathrm{Mn}$, o que diminui a preocupação em termos de toxidade, mas chamam atenção ainda as concentrações de $\mathrm{Zn}$ e $\mathrm{Cr}$, que apresentam concentrações acima do limite legais na fração total.

\section{CONSIDERAÇÕES FINAIS}

O quadro da qualidade da água no segmento analisado do Rio São Francisco pode ser descrito por processos de contaminação que foram evidenciados em fontes pontuais já nos parâmetros físicoquímicos. Áreas com fontes difusas foram mapeadas a partir da análise especifica das concentrações dos metais pesados nas frações dissolvidas e suspensas, com destaque para a possível influência da agricultura, principalmente nas concentrações dissolvidas dos metais com maior nível de toxidade.

As contaminações por metais foram evidenciadas em duas áreas de fontes pontuais de poluição associada por influência da indústria principalmente com altos valores dos metais dissolvidos.

$\mathrm{Na}$ primeira área, uma grande quantidade de metais apresentou níveis de contaminação nos Córregos Barreiro Grande e Consciência. No Córrego Barreiro Grande, além do passivo ambiental da indústria de $\mathrm{Zn}$, também ocorrem lançamentos de esgoto doméstico, resultando em níveis de contaminação para $\mathrm{Al}$, Fe e $\mathrm{Mn}$ na fração dissolvida e para $\mathrm{Cd}$ e $\mathrm{Zn}$ dissolvido e suspenso e ainda para os metais $\mathrm{Cr}, \mathrm{Pb}$ e $\mathrm{Co}$ em suspensão. No Córrego Consciência, a contaminação ocorreu para $\mathrm{Mn}, \mathrm{Cd}$,
$\mathrm{Cr}$ e $\mathrm{Zn}$ na fração dissolvida e em suspensão para os metais $\mathrm{Pb}, \mathrm{Ni}$ e $\mathrm{Cu}$ em suspensão. Entre esses dois córregos também foi verificada contaminação por $\mathrm{Zn}$ e altas concentrações de $\mathrm{Cr}$ dissolvido. Destacam-se nesses cursos d'água os metais $\mathrm{Mn}, \mathrm{Cd}, \mathrm{Zn}$ e $\mathrm{Cr}$ quando apresentam contaminação na fração dissolvida, uma vez que esses elementos têm uma maior possibilidade de apresentar efeitos tóxicos. Quanto aos metais que se restringiram à fração em suspensão, como $\mathrm{Pb}, \mathrm{Ni}$ e $\mathrm{Cu}$, esses são removidos por processo de filtração e têm menor possibilidade de absorção por organismos, uma vez que estão adsorvidos ao material particulado em suspensão.

A amplitude da influência da contaminação da cidade de Três Marias pode ser observada em maiores concentrações no Rio São Francisco até 3 $\mathrm{km}$ a jusante da foz do Córrego Consciência. Fica evidente que a diluição das concentrações ocorre em função do próprio volume de água do Rio São Francisco, não sendo verificados valores que evidenciam o carreamento de metais, como o $\mathrm{Zn}$, que ocasionem níveis de contaminação decorrentes da influência direta dessa área.

A segunda fonte pontual urbano-industrial localizada entre Pirapora e Buritizeiro evidencia principalmente a contaminação associada aos efluentes do distrito industrial. No Córrego das Pedras, observaram-se contaminações para $\mathrm{Cu}, \mathrm{Cd}$ e $\mathrm{Ni}$; todos esses metais apresentaram níveis acima do limite ambiental já na fração dissolvida. Metais como o $\mathrm{Cu}$ e $\mathrm{Ni}$ são considerados elementos essenciais e podem entrar nos suplementos alimentares dos suínos, principalmente em confinamento, como aqueles que existem nesta subbacia. As quantidades de $\mathrm{Cd}$ podem estar relacionadas aos particulados atmosféricos do distrito industrial uma vez que alterações para $\mathrm{Cd}$ dissolvido foram observadas em outros pontos próximos à área industrial e a montante do Córrego das Pedras. 


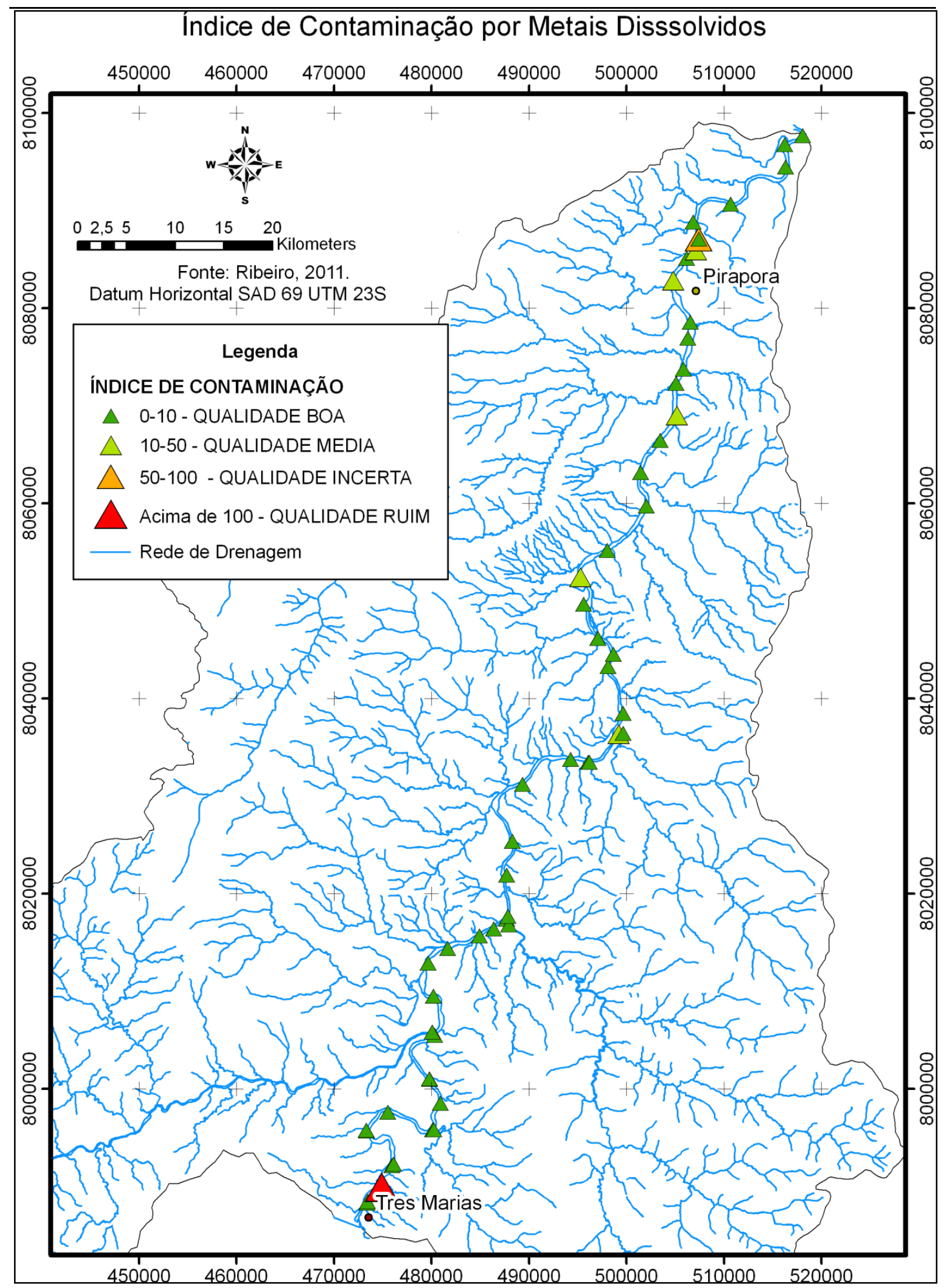

Figura 8 - Mapa de Índice de Contaminação Anual por Metais Dissolvidos 


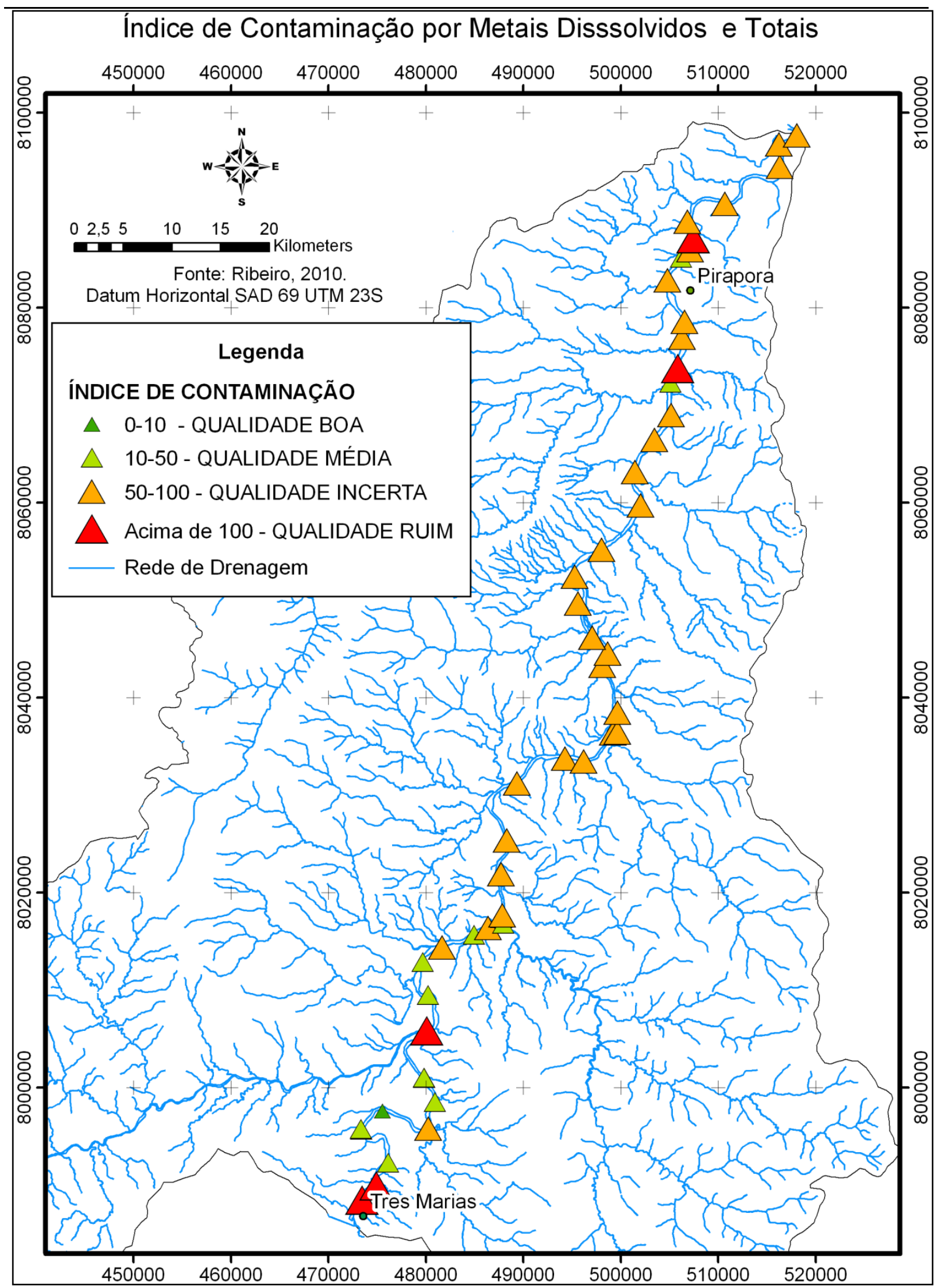

Figura 9 - Mapa de Índice de Contaminação Anual por Metais Dissolvidos e Totais. 
$\mathrm{Na}$ área do distrito industrial, contaminações para $\mathrm{Al}, \mathrm{Fe}$ dissolvido, $\mathrm{Ba}$ total e $\mathrm{Pb}$ e $\mathrm{Cr}$ em suspensão estão relacionadas ao efluente industrial liquido. Além desses, também se pode destacar um pico de $\mathrm{Zn}$ em suspensão. Próximo às indústrias, ressaltam-se contaminações por $\mathrm{Cu}, \mathrm{Cd}, \mathrm{Ni}$ e $\mathrm{Mn}$ dissolvido e para $\mathrm{Pb}$ dissolvido e em suspensão; presença desses metais alerta para a necessidade de avaliar a influência dos particulados atmosféricos no meio ambiente, uma vez que a emissão de particulados é constante e pode ter efeitos irreversíveis ao longo do tempo devido à capacidade de acumulação dos metais. Alterações para $\mathrm{Cr}$ dissolvido também foram observadas na área do distrito industrial. Os valores encontrados, apesar de se encontrarem dentro do limite permitido, revelam a entrada desse metal no sistema aquático, podendo se constituir em um problema ambiental no futuro.

Não foram verificados níveis de contaminação nesses pontos com alteração em todas as amostragens. No entanto, observam-se sempre valores mais altos em relação aos demais pontos a montante e a jusante da área industrial. Os níveis de contaminação se restringem aos pontos mais próximos à área industrial e de lançamento do efluente, sendo diluídos a jusante. É necessário destacar, no entanto, que essas concentrações de metais não são mais removidas, e o seu acúmulo constante, mesmo pontual, pode ter efeitos na biota em um futuro próximo em uma dezena de anos, caso a entrada destes elementos não seja controlada.

$\mathrm{Na}$ análise da influência da agropecuária foram consideradas mudanças significativas para os metais pesados ao longo do segmento analisado. A diferença nas concentrações dos metais no perfil é bastante diferenciada para as concentrações dissolvidas de $\mathrm{Cu}, \mathrm{Cd}, \mathrm{Cr}$, Co e $\mathrm{Ni}$ que ocorreram somente nestes pontos do segmento estudado.

Para essas fontes difusas de poluição, principalmente de origem agrícola, e considerando sobretudo os resultados para a fração dissolvida dos metais, verificaram-se dois conjuntos de variação espacial nas concentrações de alguns elementos: no segmento a jusante do Rio de Janeiro, a montante da cidade de Pirapora e na área do Projeto de Fruticultura, a jusante da cidade de Pirapora.

As atividades agrícolas se intensificam a jusante da sub-bacia Rio de Janeiro, onde o espaço rural começa a diversificar-se, sobrepondo-se ao predomínio do eucalipto a produção de grãos e o sistema irrigado. Esse segmento com maior concentração de atividades agrícolas irrigadas refere-se ao trecho entre a sub-bacia do Rio de Janeiro e as cidades de Buritizeiro e Pirapora nas margens esquerda e direita respectivamente. A jusante desses centros urbanos, tem-se a produção de frutas na margem direita até a montante da foz do Rio das Velhas.

Nessa área agrícola, verificou-se a presença de $\mathrm{Cu}$ e $\mathrm{Cd}$ dissolvido, que foram observados somente na área com uso agrícola mais intenso. Os valores de $\mathrm{Cu}, \mathrm{Cd}$ encontram-se entre o Limite de Detecção e o Limite de Quantificação e têm sido verificados nessa mesma área na amostragem de março, julho e outubro até a montante de Pirapora. Vale ressaltar que esses foram os únicos pontos onde foram obtidas leituras para esses metais além da área industrial. Comportamento semelhante é observado para os metais $\mathrm{Cr}$ e Co dissolvido. No entanto, o Co dissolvido abrange uma área maior até a área do projeto de fruticultura, onde as concentrações de $\mathrm{Cr}$ em suspensão também são maiores.

Concentrações de $\mathrm{Ni}$ dissolvido também foram encontradas nessa área, mas, diferentemente dos demais metais, as alterações foram observadas para o Ni nas frações dissolvida e em suspensão nos mesmos pontos. Essas alterações foram observadas entre o Ribeirão do Atoleiro e a montante da llha dos Prazeres em outubro e no Ribeirão do Atoleiro e no Córrego Cedro em março.

O Ba também apresentou alterações na área agrícola. Concentrações maiores de $\mathrm{Ba}$ dissolvido foram notados a montante de Pirapora principalmente na amostragem de outubro. Esse período coincide com a época de preparação do solo para a agricultura, ficando mais propenso à liberação de metais com as primeiras chuvas que antecedem as plantações do denominado plantio de verão (soja sequeiro, milho, café, e algodão). Existe também plantio da soja irrigada e milho safrinha nos meses de fevereiro e março, assim como foi refletido nas alterações para Ba em março. Nessa área, destacamse as alterações na foz do Rio do Formoso, do Ribeirão do Atoleiro e dos Córregos Cedro e Marambaia.

$\mathrm{Na}$ área do Projeto de Fruticultura, o ponto com maiores concentrações refere-se ao mais próximo da área de plantio, local inclusive onde está instalada a estação de captação de água da CODEVASF. Nessa área, chamam atenção os níveis de $\mathrm{Cd}, \mathrm{Cr}$, $\mathrm{Co}$, Ba e $\mathrm{Mn}$, que podem estar relacionados aos produtos agroquímicos utilizados e ao manejo das culturas.

Essas alterações descritas acima não confirmam a contaminação por esses metais, uma vez que na maioria dos pontos os valores estavam abaixo do limite de quantificação. No entanto, fica evidente a diferença no comportamento desses metais nesse trecho do Rio São Francisco, sendo necessária a realização de estudos mais específicos nos solos agrícolas. Apesar de os valores encontrados ainda 
serem baixos, a chegada de contaminantes de origem agrícola em altas concentrações nos cursos d'água representa alto nível de contaminação, tendo em vista o percurso percorrido por esses contaminantes.

Esses resultados fornecem embasamento para o desenvolvimento de estudos mais específicos no sentido de avaliar as influências das atividades agropecuárias na qualidade da água do Rio São Francisco.

Os níveis de contaminação associados aos metais em suspensão ( $\mathrm{Mn}, \mathrm{Zn}$ e $\mathrm{Cr}$ ) não são os maiores problemas no que se refere à qualidade da água, pois, apesar de apresentarem uma distribuição espacial mais ampla, suas concentrações apresentam maior dificuldade de entrada na cadeia alimentar, uma vez que estão associados ao material particulado em suspensão. Para as águas usadas para consumo humano, as partículas em suspensão são removidas por processos de tratamento convencional, como é especificado pela legislação ambiental (Resolução CONAMA 357) para a classe do Rio São Francisco no segmento, no entanto o tratamento convencional (filtração) não remove os metais dissolvidos podendo ser um problema em relação ao consumo de água.

A qualidade da água pode ser descrita a partir dos parâmetros físico-químicos e das concentrações especificas dos metais que não atendem os requisitos de uso e, portanto, os padrões de qualidade. Nesse sentido, a análise dos Índices de Contaminação encontrados nesse segmento mostra que tanto os dados físico-químicos quanto as concentrações dos metais alertam para o comprometimento da qualidade da água na área urbana e industrial. Nesse contexto, destacam-se os supracitados córregos Consciência e Barreiro Grande, no segmento entre esses dois pontos e a jusante do Córrego Consciência, na região de Três Marias. Em Pirapora, chama atenção a inadequação da qualidade da água no Córrego das Pedras em Buritizeiro e no segmento localizado próximo ao centro urbano até a área do efluente industrial liquido.

Em relação à área entre os dois centros urbanos, a qualidade da água fica comprometida quando considerada a fração em suspensão principalmente na estação chuvosa. A influência dos metais dissolvidos fica restrita às concentrações de Fe e Al.

As alterações encontradas para os metais dissolvidos mostram a necessidade de se estabelecer um programa de monitoramento da qualidade da água com uma rede mais densa que permita acompanhar melhor as fontes difusas de poluição como as de origem agrícola.
Quanto à comparação entre os limites estabelecidos pela legislação ambiental e a metodologia utilizada, a Resolução CONAMA 357 não estabelece a metodologia para a análise dos metais totais, sendo adotado neste trabalho o procedimento de digestão ácida comumente mencionada na literatura. É importante enfatizar a necessidade do estabelecimento da metodologia na legislação visando a validar comparações entre os estudos ambientais.

A análise da contaminação por metais mostrouse eficiente no que se refere ao estudo da qualidade da água, corroborando com a necessidade da integração dos metais mais tóxicos nos Índices de Qualidade da Água.

As condições da qualidade da água observadas neste estudo ainda podem ser consideradas boas em termos de contaminação por metais pesados. Os dados apresentados nesta pesquisa permitem visualizar a variação da qualidade da água no Rio São Francisco e os principais pontos de intervenção para as ações preventivas e corretivas.

Portanto, ressalta-se a necessidade de implementação da Política Nacional de Recursos Hídricos e seus respectivos instrumentos, visando à melhoria dos processos de gestão e, consequentemente, da qualidade da água na bacia do Rio São Francisco.

Contribuição apresentada no "International Symposium Workshop on Mining activities, refineries, pollution control and remediation strategies", realizado no IGC-UFMG (Belo Horizonte, 12 a 20 de setembro de 2011).

\section{REFERÊNCIAS}

Baird, C. 2. ed. 2002. Química Ambiental. Porto Alegre, Bookman, $621 p$.

Branco, S.M. \& Rocha, A.A. 1997. Poluição, proteção e usos múltiplos de represas. São Paulo, Edgard Blucher, 185p.

Conama. 2005. Conselho Nacional de Meio Ambiente. Resolução 357 de Março de 2005. Disponível em: www.mma.gov.br/conama acesso em: 22/03/ 2008.

Eleutério, L. 1997. Diagnóstico da situação ambiental da cabeceira do rio Doce, MG, no âmbito das contaminações por metais pesados em sedimentos de fundo. Dissertação de Mestrado, Escola de Minas, Universidade Federal de Ouro Preto, 137p.

Esteves, F.A. 2 ed. 1998. Fundamentos de Limnologia. Rio de Janeiro, Interciência, 602p.

Fellenberg, G. 1980. Introdução aos problemas da poluição ambiental. São Paulo, EPU Springer. Ed. da Universidade de São Paulo,302p.

Forstner, U. \& Muller, G. 1974. Schwermetalle in Flussen und Seen als ausdruck der umweltverschumuzung. New York, SpringerVerlag, $225 \mathrm{p}$. 
Hermes, L.C. 2004. Avaliação da qualidade das Águas: manual prático. Brasília, Embrapa Informação Tecnológica, 55p.

Larcerda, L.D. 1992. Trace Metals in sediment sores from remote lakes of the Pantanal, A Central Brazil. Geochimica Brasiliensis (Rio de Janeiro), v. 6, n. 2, p. 103-109.

Laybauer, L. 1995. Análise das transferências de metais pesados em água e sedimentos fluviais na região das minas do Camaquã, RS. Instituto de Geociências, UFRGS, Dissertação de Mestrado,164p.

Libâneo, M. Ed.2. 2008. Fundamentos de qualidade e tratamento de Água. Campinas, Editora Átomo, 449p.

Lundhamer, S. 1991. Distribuição dos Metais Pesados nos Sedimentos e na Água do Rio São Francisco a Jusante de Três Marias. In: ENESMA, 4, 1993, Cuiabá, Anais do $4^{\circ}$ Encontro Nacional de Estudos Sobre o Meio Ambiente. Cuiabá, UFMT.

Macêdo, J.A. 1ạ Ed. B. 2002. Introdução à Química Ambiental. Juiz de Fora, Jorge Macedo, 487p.

Magalhães Jr., A.P. 2007 Indicadores Ambientais e Recursos Hídricos: Realidade e Perspectivas para o Brasil a partir da Experiência Francesa. Rio de Janeiro, Bertrand Brasil, 688p.

Malavolta, E. 1994. Fertilizantes e seu impacto ambiental: micronutrientes e metais pesados, mitos, mistificação e fatos. São Paulo, Produquímica, 153p.

Novothy, V. Ed. 4. 1995. Diffuse Sources of pollution by Toxic Metal and Impact on receiving Waters. In: salomons, W.
Heavy Metals: Problems and Solutions. New York, Springer Cap. 3, p. 32-52.

Oliveira, M.R. 2007. Investigação da contaminação por metais pesados da água e do sedimento de corrente nas margens do rio São Francisco e tributários, a jusante da represa da CEMIG, no município de Três Marias, Minas Gerais. Tese de Doutorado. Instituto de Geociências, Universidade Federal de Minas Gerais, 149 p.

Oliveira, M.R.; Roeser, H.M.P. \& Horn, A.H. 2005. Concentração de metais pesados nos sedimentos de corrente no parque estadual do itacolomi e arredores, MG. Geonomos, 13(12): 83-90.

Ribeiro, E.V. 2010. Avaliação da Qualidade da Água do Rio São Francisco no Segmento entre Três Marias e Pirapora - MG: Metais Pesados e Atividades Antropogênicas. Dissertação de Mestrado. Instituto de Geociências, Universidade Federal de Minas Gerais, $196 \mathrm{p}$

Rodrigues, A.S.L. \& Nalini Jr, H.A. 2009. Valores de background geoquímico e suas implicações em estudos ambientais. REM: R. Esc. Minas, Ouro Preto, V. 62(2): 155-165, (abr. jun).

Von Sperling, M. Estudos de Modelagem da qualidade da água de rios. Belo Horizonte, Departamento de Engenharia Sanitária e Ambiental. Universidade Federal de Minas Gerais, 2007.588p. (Princípios do tratamento biológico de águas residuárias, 7).

1 Discussão do termo em Chemistry International, Vol 23 No 6 November 2001 - Heavy Metals - A Meaningless Term por John H. Duffus. 